\title{
Immunoinformatics Approach for Multiepitope Vaccine Prediction from H, M, F, and N Proteins of Peste des Petits Ruminants Virus
}

\author{
Bothina B. M. Gaafar, ${ }^{1}$ Sumaia A. Ali $\mathbb{D}^{1,2}$ Khoubieb Ali Abd-elrahman, ${ }^{3}$ \\ and Yassir A. Almofti ${ }^{1}$ \\ ${ }^{1}$ Department of Molecular Biology and Bioinformatics, College of Veterinary Medicine, University of Bahri, Khartoum, Sudan \\ ${ }^{2}$ Department of Veterinary Medicine and Surgery, College of Veterinary Medicine, \\ Sudan University of Science and Technology, Sudan \\ ${ }^{3}$ Department of Pharmaceutical Technology, College of Pharmacy, University of Medical Science and Technology (UMST), \\ Khartoum, Sudan
}

Correspondence should be addressed to Yassir A. Almofti; yamofti99@gmail.com

Received 30 April 2019; Accepted 2 August 2019; Published 30 October 2019

Guest Editor: Masha Fridkis-Hareli

Copyright (C) 2019 Bothina B. M. Gaafar et al. This is an open access article distributed under the Creative Commons Attribution License, which permits unrestricted use, distribution, and reproduction in any medium, provided the original work is properly cited.

\begin{abstract}
Background. Small ruminant morbillivirus or peste des petits ruminants virus (PPRV) is an acute and highly contagious viral disease of goats, sheep, and other livestock. This study aimed at predicting an effective multiepitope vaccine against PPRV from the immunogenic proteins haemagglutinin $(\mathrm{H})$, matrix $(\mathrm{M})$, fusion $(\mathrm{F})$, and nucleoprotein $(\mathrm{N})$ using immunoinformatics tools. Materials and Methods. The sequences of the immunogenic proteins were retrieved from GenBank of the National Center for Biotechnology Information (NCBI). BioEdit software was used to align each protein from the retrieved sequences for conservancy. Immune Epitope Database (IEDB) analysis resources were used to predict B and T cell epitopes. For B cells, the criteria for electing epitopes depend on the epitope linearity, surface accessibility, and antigenicity. Results. Nine epitopes from the $\mathrm{H}$ protein, eight epitopes from the $\mathrm{M}$ protein, and ten epitopes from each of the $\mathrm{F}$ and $\mathrm{N}$ proteins were predicted as linear epitopes. The surface accessibility method proposed seven surface epitopes from each of the $\mathrm{H}$ and $\mathrm{F}$ proteins in addition to six and four epitopes from the $\mathrm{M}$ and $\mathrm{N}$ proteins, respectively. For antigenicity, only two epitopes ${ }_{142} P P E R V_{146}$ and ${ }_{63} D P L S P_{67}$ were predicted as antigenic from $\mathrm{H}$ and $\mathrm{M}$, respectively. For T cells, MHC-I binding prediction tools showed multiple epitopes that interacted strongly with BoLA alleles. For instance, the epitope ${ }_{45} M F L S L I G L L_{53}$ from the $\mathrm{H}$ protein interacted with four BoLA alleles, while ${ }_{276} F K K I L C Y P L_{284}$ predicted from the $\mathrm{M}$ protein interacted with two alleles. Although $\mathrm{F}$ and $\mathrm{N}$ proteins demonstrated no favorable interaction with B cells, they strongly interacted with T cells. For instance, ${ }_{358} S T K S C A R T L_{366}$ from the F protein interacted with five alleles, followed by ${ }_{340} S$ QNALYPMS ${ }_{348}$ and ${ }_{442} I D L G P A I S L_{450}$ that interacted with three alleles each. The epitopes from the $\mathrm{N}$ protein displayed strong interaction with BoLA alleles such as ${ }_{490} R S A E A L F R L_{498}$ that interacted with five alleles, followed by two epitopes ${ }_{2} A T L L K S L A L_{10}$ and ${ }_{304} Q Q L G E V A P Y_{312}$ that interacted with four alleles each. In addition to that, four epitopes ${ }_{3} T_{L L K S L A L F},{ }_{11}{ }_{356}$ FPAYFRL ${ }_{364},{ }_{360} A Y F R L G Q E M_{368}$, and ${ }_{412} P_{R Q A Q V S F L} L_{420}$ interacted with three alleles each. Conclusion. Fourteen epitopes were predicted as promising vaccine candidates against PPRV from four immunogenic proteins. These epitopes should be validated experimentally through in vitro and in vivo studies.
\end{abstract}

\section{Introduction}

Small ruminant morbillivirus (previously called peste des petits ruminants virus (PPRV)) is one of the most damaging ruminant diseases. It is among the priority diseases indicated in the FAO-OIE Global Framework for the Progressive Control of Transboundary Animal Diseases (GF-TADs) in the 5year Action Plan $[1,2]$. PPRV is one of the top ten diseases in 
sheep and goats that are having a high impact on the poor rural small ruminant farmers [3]. The disease is considered an acute and highly contagious viral disease with a high morbidity and mortality rate in small ruminants, such as goats and sheep and related wild animals $[4,5]$. The disease is characterized by high fever, depression, anorexia, ocular and nasal discharge, pneumonia, necrosis and ulceration of mucous membranes, and inflammation of the gastrointestinal tract leading to severe diarrhea $[6,7]$. It causes high death rates in goats and sheep up to $100 \%$ and $90 \%$, respectively. However, sheep can be subclinically infected and play a major role in the silent spread of PPRV over large distances and across borders [1]. The disease is widely distributed in Africa, on the Arabian Peninsula, and in the Middle East and Asia [5, 8, 9]. Morbilliviruses are rapidly inactivated at environmental temperature by solar radiation and desiccation. This indicated that the transmission occurred by direct contact with infected animals or their excretions. Transmission of PPRV occurs primarily by droplet infection but may also occur by ingestion of contaminated feed or water [6].

PPRV is an enveloped single strand of negative sense RNA virus, belonging to the genus Morbillivirus, in the family Paramyxoviridae which is closely related to rinderpest virus (RPV), canine distemper virus (CDV), and measles virus $(\mathrm{MeV})[5,10,11]$. The genome of morbilliviruses is organized into six transcriptional units encoding six structural proteins. These structural proteins include the nucleoprotein ( $\mathrm{N}$ protein), matrix protein ( $\mathrm{M}$ protein), polymerase or large protein (L protein), phosphoprotein (P protein), and two envelope glycoproteins, the haemagglutinin protein ( $\mathrm{H}$ protein) and the fusion protein ( $\mathrm{F}$ protein) [12-14]. The $\mathrm{N}$ protein played an important role in the viral life cycle, interacting with both viral and cellular proteins. It also interacted with the viral RNA to form the nucleocapsid structures seen in both the virions and infected cells [13]. The viral $\mathrm{L}$ and $\mathrm{P}$ proteins interact with the nucleocapsids to form the functional transcription/replication unit of the virion [13]. The C-termini of morbillivirus $\mathrm{N}$ proteins also interacted with cellular regulatory proteins such as heat shock protein Hsp72, interferon regulator factor- (IRF-) 3, and a novel cell surface receptor (genetically engineered receptor) [13]. The F protein facilitated the virus penetration of the host cell membrane. This protein is also critical for the induction of an effective protective immune response [15]. The $\mathrm{M}$ protein of paramyxoviruses forms an inner coat to the viral envelope and thus serves as a bridge between the surface viral glycoproteins and the ribonucleoprotein core. By virtue of its position, $\mathrm{M}$ appeared to play a central role in viral assembly by formation of new virions which were liberated from the infected cell by budding $[16,17]$. Interaction of the PPRV $\mathrm{H}$ and $\mathrm{F}$ proteins with the host plasma membrane led to viral entry by binding of the $\mathrm{H}$ protein to receptors [17]. Generally, the protective cell-mediated and humoral immune responses against morbilliviruses are directed mainly against $\mathrm{H}, \mathrm{F}, \mathrm{M}$, and $\mathrm{N}$ proteins. Moreover, PPRV is genetically grouped into four distinct lineages (I, II, III, and IV) based on the analysis of the fusion (F) gene. This classification of PPRV into lineages has broadened the understanding of the molecular epidemiology and worldwide movement of PPR viruses [7, 18-20].

Vaccination is the main tool for controlling and eradicating the PPR virus [12]. Despite the fact that live attenuated vaccines have been widely used to protect small ruminants against circulating PPRV $[1,3,7]$, the continuous spread of PPR disease indicated two possible hypotheses. The first is the emergence of new PPRV strains with new genetic makeup and greater fitness in the face of vaccine-elicited protection. The second is the lapses in regulatory control that ultimately lead to movement of diseased/infected individuals across the region/state/country without proper monitoring and surveillance [1].

The advances made in the field of immunoinformatics tools coinciding with the knowledge on the host immune response lead to new disciplines in vaccine design against diseases via computer in silico epitope predictions. The epitopedriven vaccine is a new concept that is being successfully applied in multiple studies, particularly to the development of vaccines targeting conserved epitopes in variable or rapidly mutating pathogens [21-23]. The identification of specific epitopes derived from infectious disease has significantly advanced the development of peptide-based vaccines. Peptides elicited more desirable manipulation of immune response through the use of the $\mathrm{B}$ cell epitopes. These epitopes mainly induce antibody production from B cells and cellular response and cytokine secretion from $\mathrm{T}$ cells. The approach regarding the molecular basis of antigen recognition and HLA binding motifs to host class I and class II MHC proteins is highly supported by the immunoinformatics which aids in designing epitope-based vaccine motifs that serve as therapeutic candidates for many infectious diseases [24].

The main objective of this study was to analyze multiple immunogenic proteins from the PPR genome for designing a safe multiepitope vaccine using immunoinformatics tools present in the Immune Epitope Database (IEDB). These proteins include haemagglutinin protein $(\mathrm{H})$, matrix protein $(\mathrm{M})$, fusion protein $(\mathrm{F})$, and nucleoprotein $(\mathrm{N})$ sequences of PPRV strains reported in the (NCBI) database.

\section{Materials and Methods}

2.1. Sequence Retrieval. Four immunogenic protein sequences of PPRV (updated August 2018) were retrieved from GenBank of the National Center for Biotechnology Information (NCBI) (http://www.ncbi.nlm.nih.gov/protein) in Oct. 2018. These included 82 sequences from the haemagglutinin protein $(\mathrm{H}$ protein), 67 sequences from the matrix protein (M protein), 94 sequences from the fusion protein ( $\mathrm{F}$ protein), and 80 sequences from the nucleoprotein ( $\mathrm{N}$ protein). All sequences were retrieved in FASTA format. The retrieved sequences, their accession numbers, and geographical locations are listed in Tables $1-4$.

2.2. Phylogenetic Evolution. A phylogenetic tree of the retrieved sequences of each immunogenic protein was constricted using MEGA7.0.26 (7170509) software [25]. 


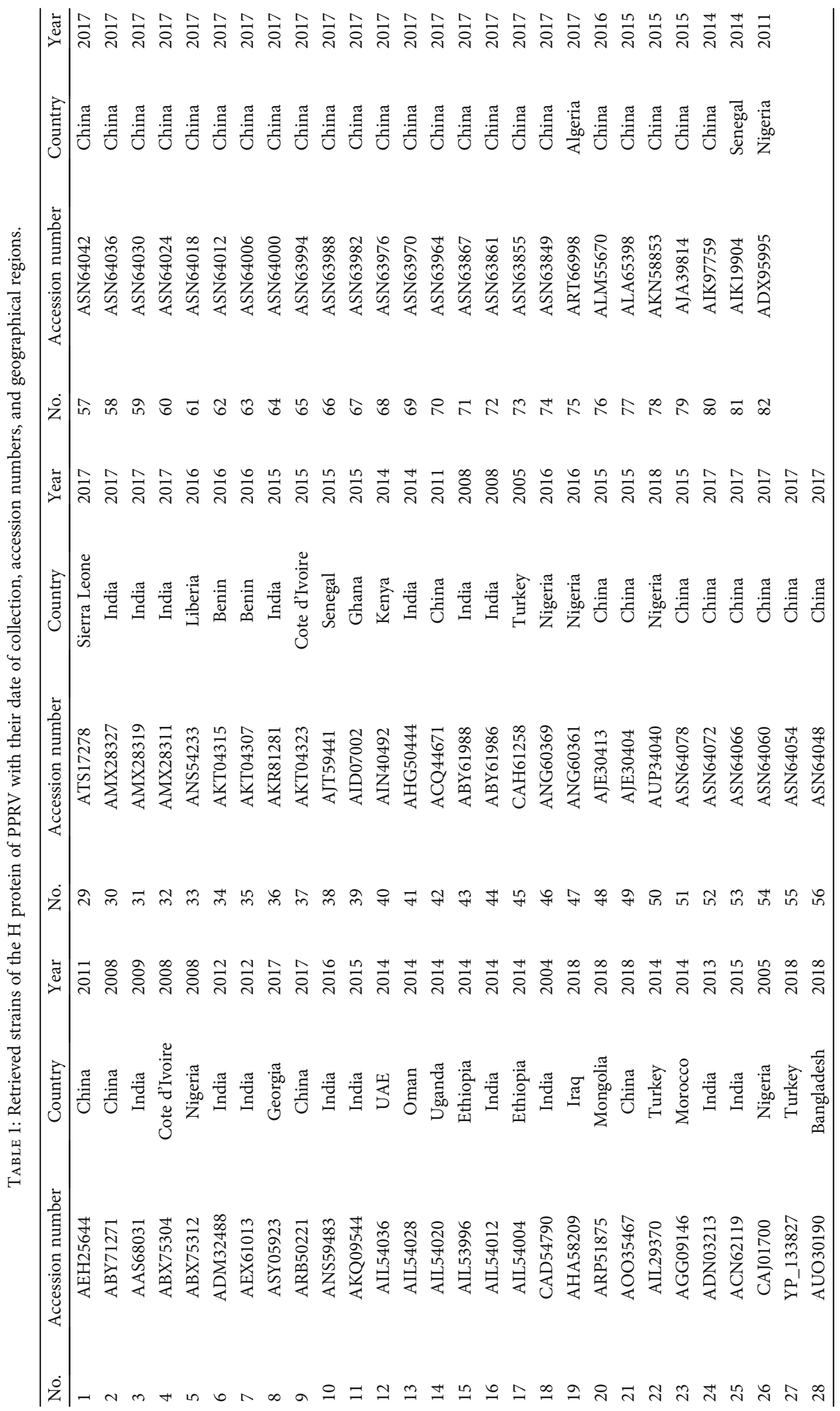




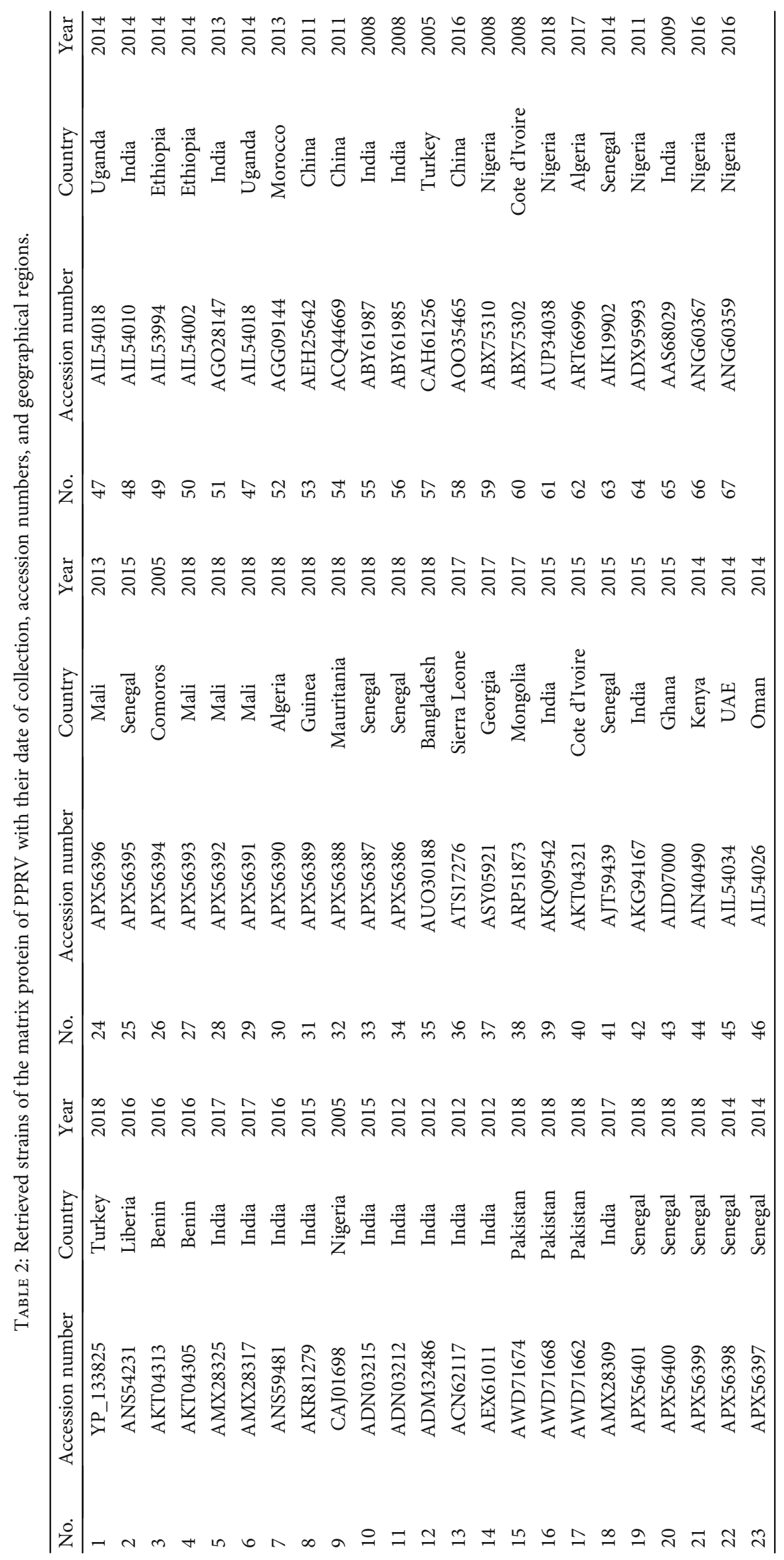




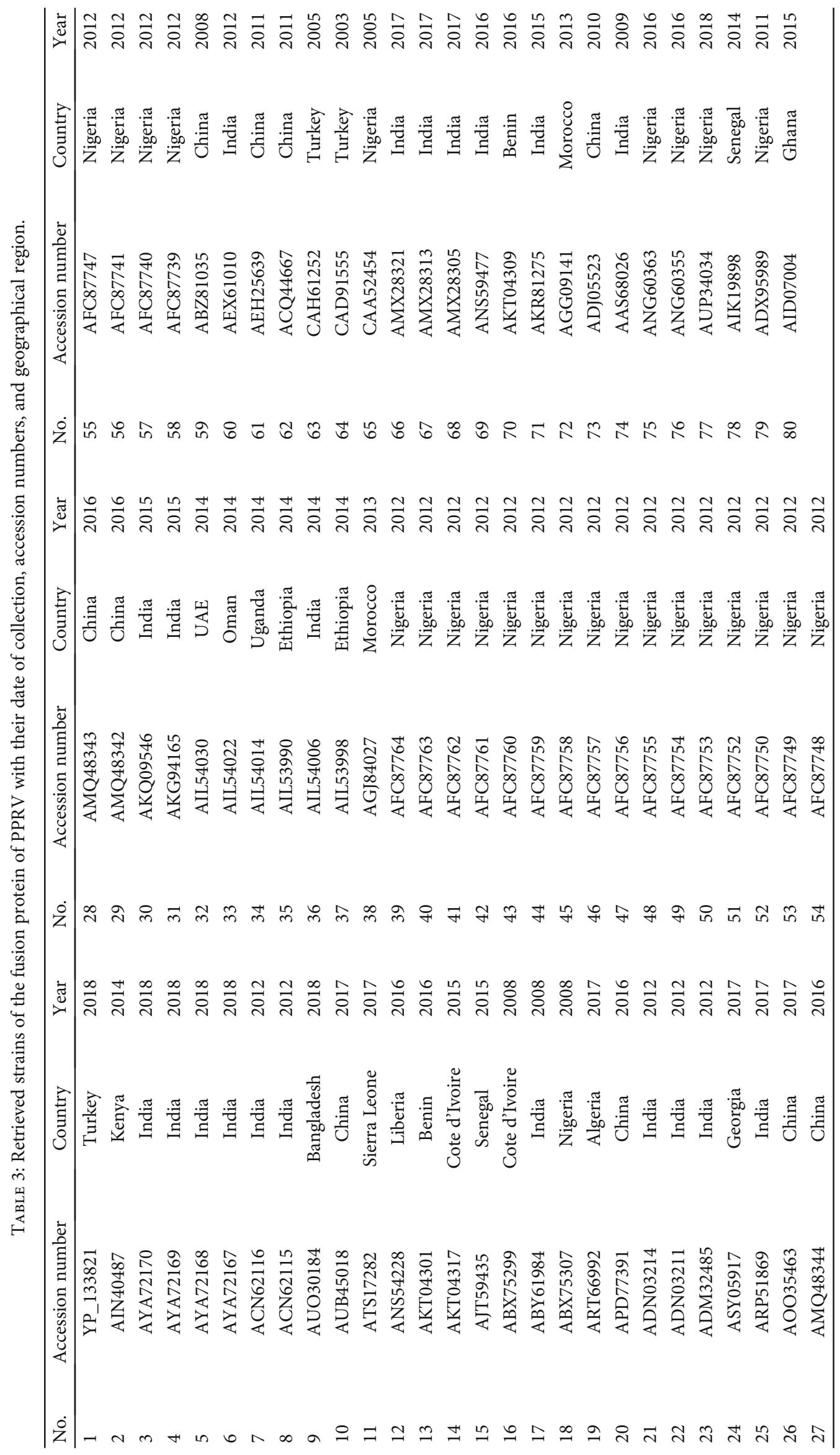




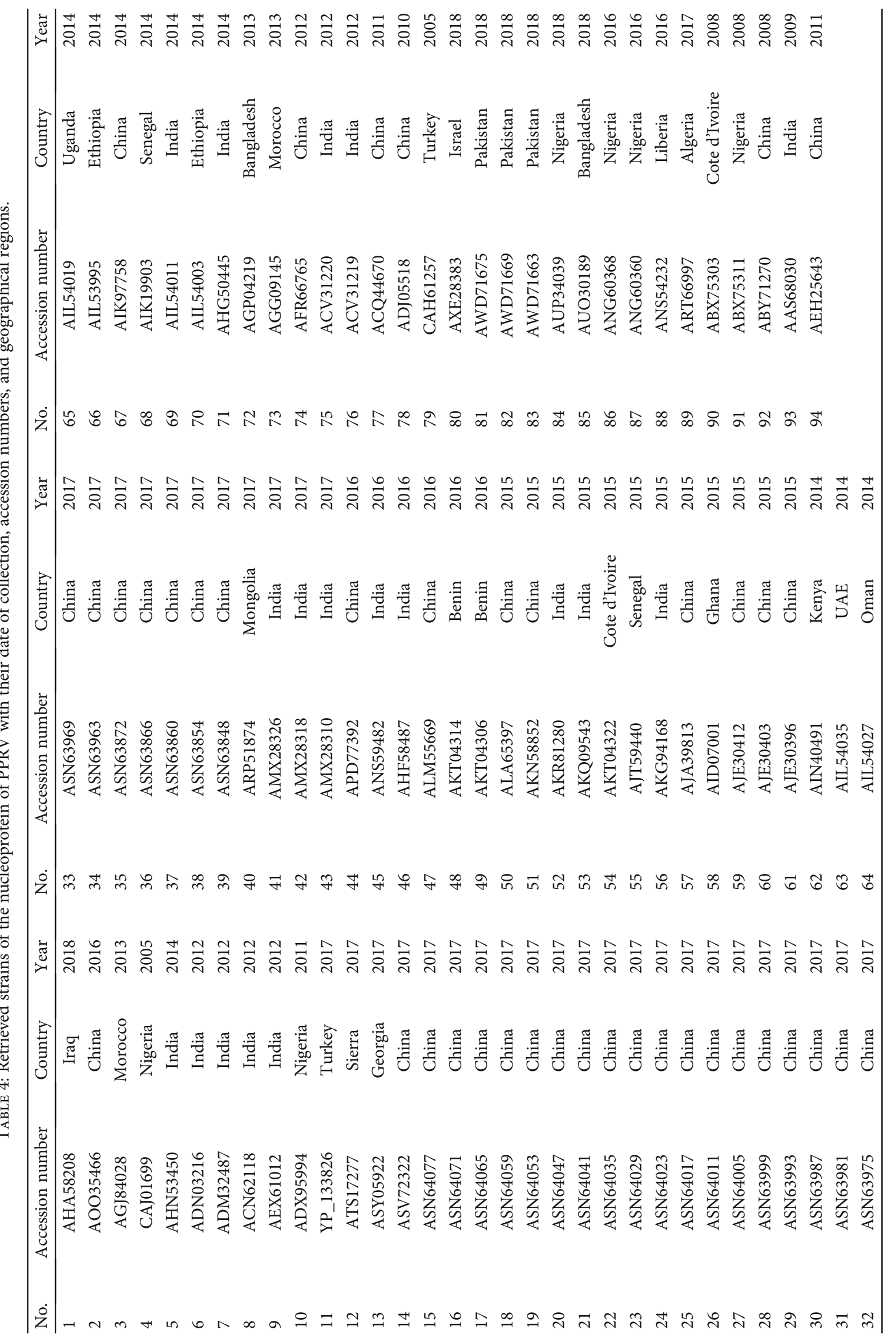






Figure 1: Phylogenetic tree of retrieved strains of $\mathrm{H}$ and $\mathrm{M}$ proteins. The retrieved strains demonstrated divergence in their common ancestors. 

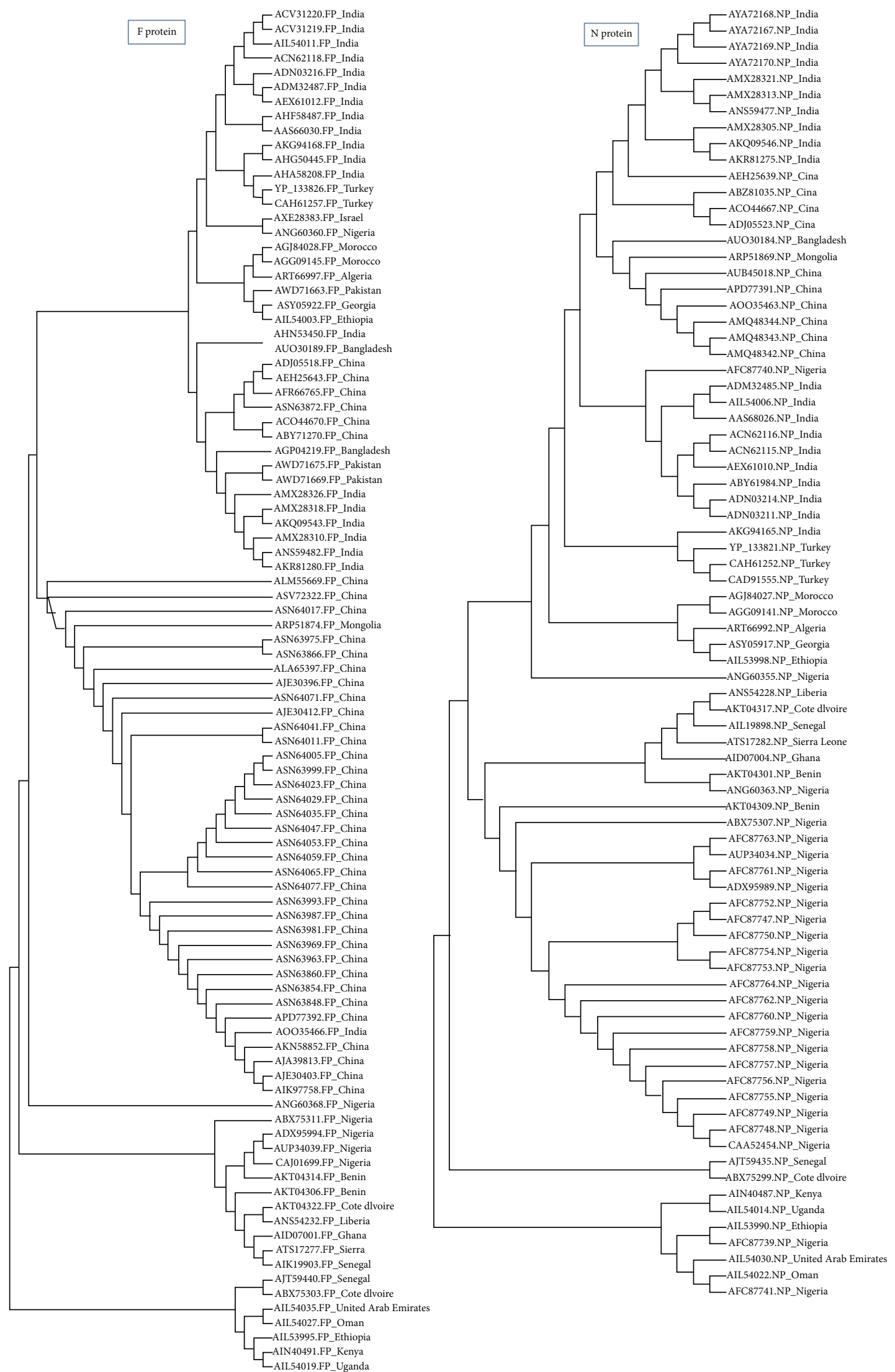

FIGURE 2: Phylogenetic tree of retrieved strains of $\mathrm{F}$ and $\mathrm{N}$ proteins. The retrieved strains demonstrated divergence in their common ancestors. 


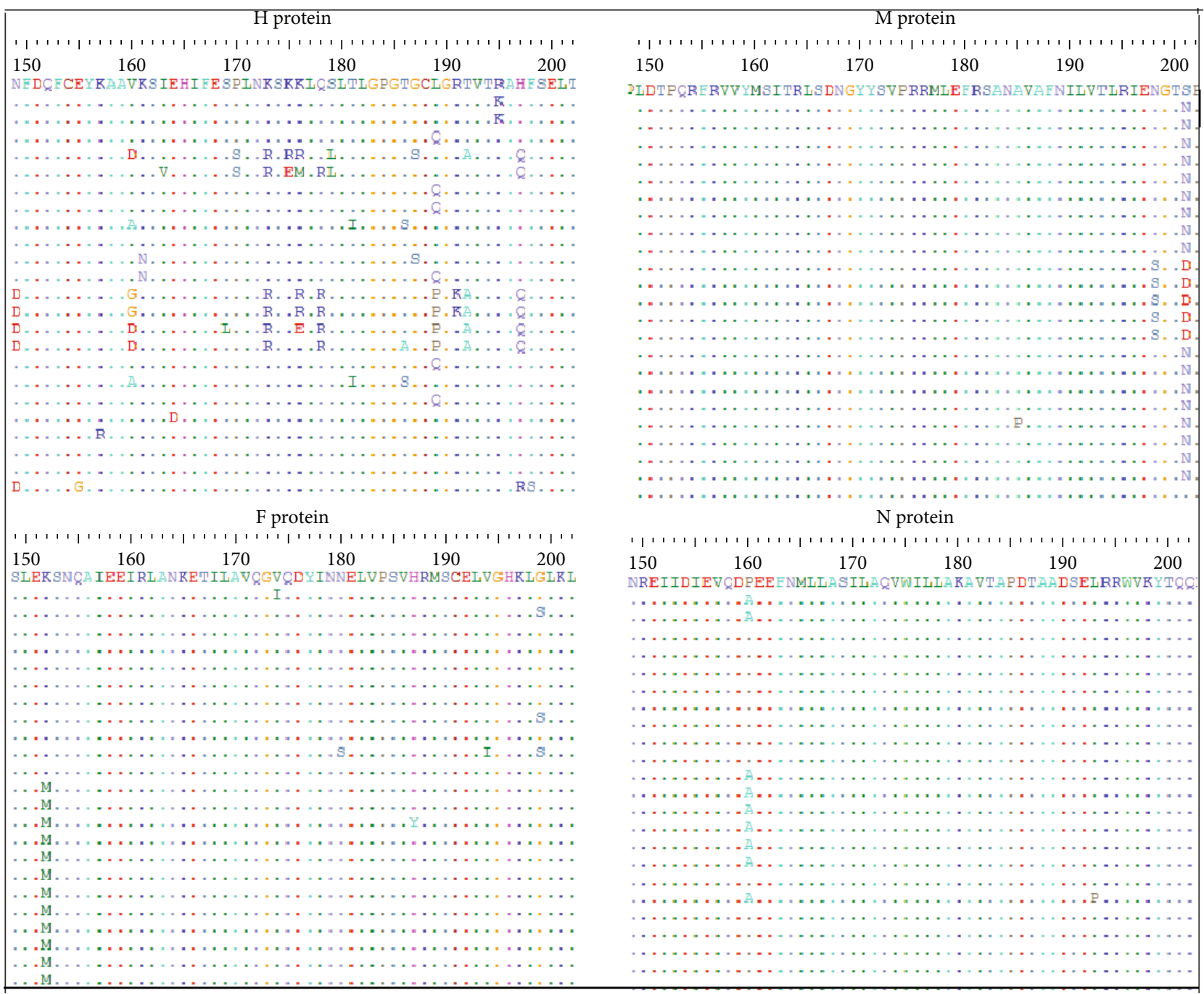

Figure 3: Multiple sequence alignment (MSA) of the retrieved strains of H, M, F, and N proteins using BioEdit software and ClustalW. Dots indicate the conservancy of the retrieved strains, and letters within the aligned sequences indicate no conservancy (mutation) in the amino acid.

Each protein tree was constructed using the maximum likelihood parameter in the software.

2.3. Multiple Sequence Alignment. The complete protein sequences of each immunogenic protein of PPRV were aligned via BioEdit software (version 7.2.5) to generate a multiple sequence alignment (MSA) with the ClustalW tool [26].

2.4. Epitope Prediction. Several immunobioinformatics tools were used for prediction of multiple epitopes from the four immunogenic proteins of PPRV. Tools from the Immune Epitope Database analysis resource (http://www.iedb.org/) [27] were used to analyze the immunogenic proteins. The input was the reference sequences of $\mathrm{H}$ protein ( $\mathrm{YP}$ 133827.2), $M$ protein (YP_133825.1), $\mathrm{F}$ protein (YP_ 133826.1), and N protein (YP_133821.1). They were submitted to Epitope Analysis Resources to predict B and T cell epitopes. The predicted epitopes were further investigated in aligned retrieved sequences for conservancy to identify the proposed candidate epitopes.
2.4.1. B Cell Epitope Prediction. Epitopes that interacted with the $\mathrm{B}$ lymphocytes are a discrete part from the antigenic molecule that is recognized by the B cell receptor and elicited immunoglobulin production. These predicted epitopes are characterized by their surface accessibility and their antigenic reactivity with the immunoglobulins of the humoral immunity [24]. Epitope prediction tools of the Immune Epitope Database (IEDB) at http://tools.iedb.org/bcell/ [27] were used for this purpose. Linear B cell epitopes were predicted by BepiPred linear epitope prediction (http://tools.iedb.org/bcell/result/) [28]. The Emini surface accessibility prediction tool was performed to detect the surface accessible epitopes (http:// tools.iedb.org/bcell/) [29], while prediction of antigenic epitopes was performed to identify the antigenic determinants on proteins based on the physicochemical properties of amino acid residues using the Kolaskar and Tongaonkar antigenicity method (http://tools.immuneepitope.org/bcell/) [30].

2.4.2. Cytotoxic T Lymphocyte Epitope Prediction. IEDB tools (http://tools.iedb.org/mhci/) were used to predict different 

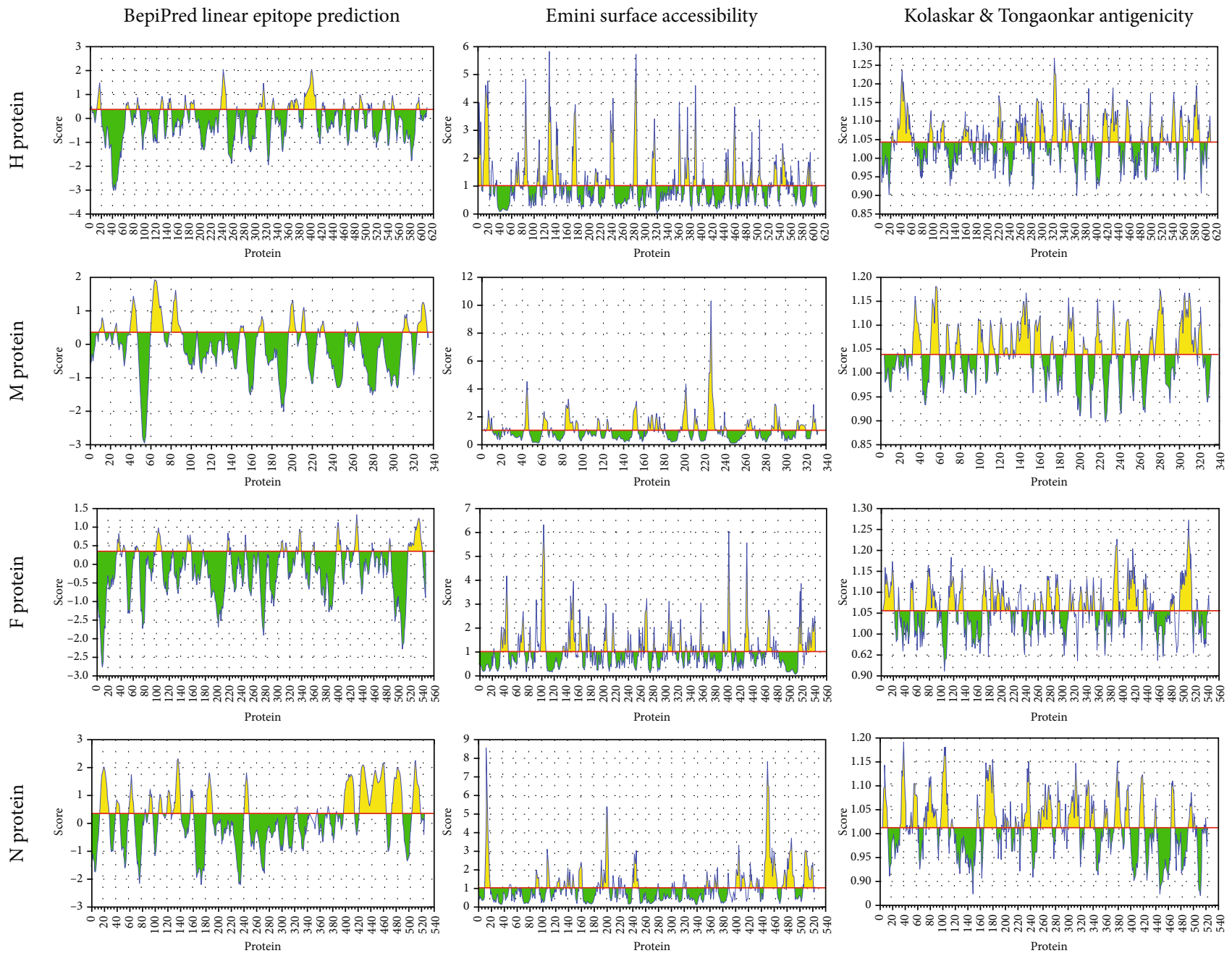

— Threshold

FIGURE 4: Prediction of B cell epitopes by different IEDB scales (BepiPred linear epitope prediction, Emini surface accessibility, and Kolaskar and Tongaonkar antigenicity prediction) for $\mathrm{H}, \mathrm{M}, \mathrm{F}$, and N proteins. Regions above the threshold (red line) were proposed as a part of the B cell epitope while regions below the threshold (red line) were not.

cytotoxic T cell (CTL) epitopes that bind to the major histocompatibility complex class I alleles (MHC class I) [31]. Analysis was done using cow alleles (BoLA-D18.4, BoLAHD6, BoLA-JSP.1, BoLA-T2a, BoLA-T2b, and BoLA-T2c). An artificial neural network (ANN) was used to predict the binding affinity $[32,33]$. The peptide length for all selected epitopes was set to 9 amino acids (9mers). Percentile rank required for the peptide's binding to the specific MHC-I molecules was set in the range from 1 to 3 .

\subsection{Homology Modeling}

2.5.1. The Three-Dimensional (3D) Structures of the Reference Sequences of $P P R V$. The prediction of the three-dimensional (3D) structure of $\mathrm{H}, \mathrm{M}$, and $\mathrm{F}$ protein reference sequences of PPRV was performed using the RaptorX structure prediction server (http://raptorx.uchicago.edu/StructurePrediction/ predict/) [34-36], while the $\mathrm{N}$ protein sequence was submitted to the SPARKS-X server (http://sparks-lab.org/yueyang/
server/SPARKS-X/) [37]. The 3D structure of each protein reference sequence was later treated with Chimera software 1.8 to show the position of proposed epitopes [38].

\section{Results and Discussion}

The validity and benefits of peptide vaccines designed by bioinformatics tools had been verified by appreciable research [24]. The availability of the complete genome, proteome sequences, and pathogenesis of many pathogenic microorganisms contributed to the production of a vaccine through bioinformatics $[24,39]$. In this study, the predicted epitopes from $\mathrm{B}$ and $\mathrm{T}$ lymphocytes would help in the development of a more effective, reliable, preventive, and therapeutic vaccine against the PPRV than the conventional methods.

3.1. Phylogenetic Evolution. A phylogenetic tree was constructed using MEGA7.0.26 (7170509). The evolutionary divergence among each protein was analyzed. As shown in 


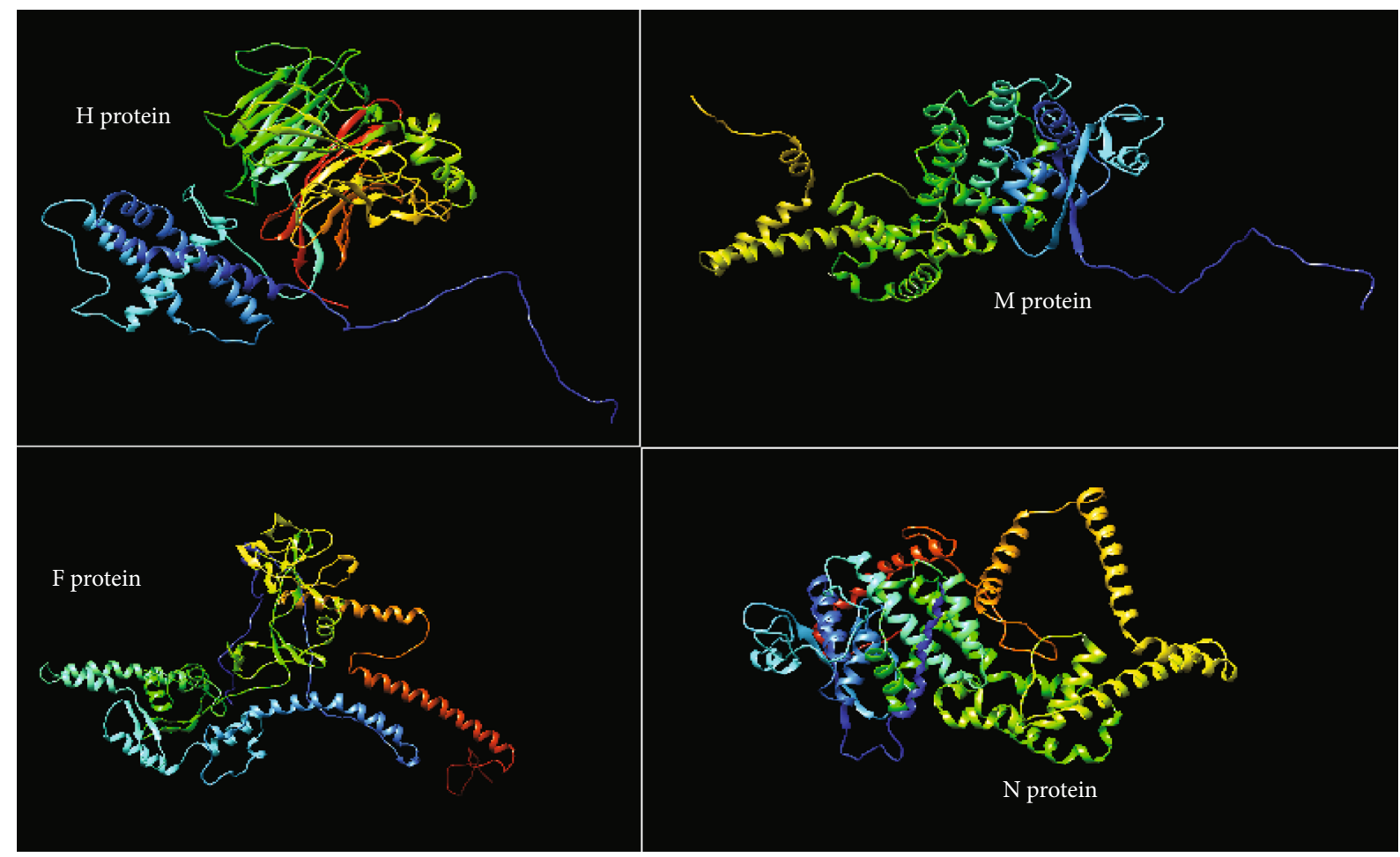

FIGURE 5: The prediction of the three-dimensional (3D) structure of $\mathrm{H}, \mathrm{M}$, and F protein reference sequences of PPRV was performed using the RaptorX structure prediction server, while the N protein sequence was submitted to the SPARKS-X server.
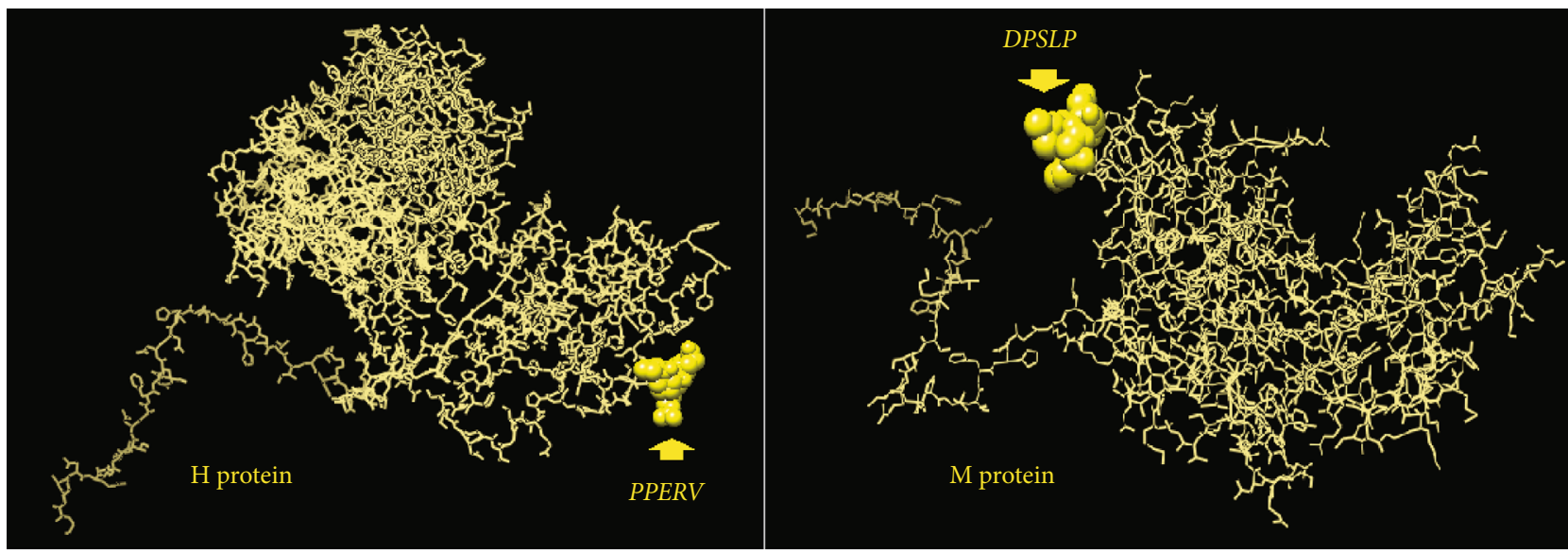

FIGURE 6: The positions of the proposed B cell epitopes in the 3D structure of the reference sequences of PPRV H and M proteins.

Figure 1, the retrieved strains of the $H$ protein revealed that Asian strains were clustered together as well as the European and African strains. However, strains from the United Arab Emirates and Oman were closely related to African strains (namely to Ethiopian strains). With regard to the phylogeny of the $M$ protein strains, the African strains were also clustered together, but among them, the Oman and United Arab Emirates strains were observed to be close to the Ethiopian strains same as those of the $\mathrm{H}$ protein. This result may indicate the transfer of the $H$ and $M$ strain segments between these countries. Also, some European and Turkish strains were clustered together. As shown in Figure 2, the retrieved strains of $\mathrm{F}$ and $\mathrm{N}$ proteins from the Asian strains were clustered together with molecular divergence among them as well as the strains retrieved from the African countries. Also, the Omanis and Emiratis strains showed close relationship to the African strains. These results indicated that these strain segments were widely distributed in Africa, Asia, Europe, and the Arab region.

3.2. Sequence Alignment. Multiple sequence alignment was performed using ClustalW in BioEdit software. As shown in Figure 3, the aligned sequences of each of the four analyzed proteins (H, M, F, and N proteins) showed considerable conservancy among the retrieved strains. However, some regions exhibited differences (mutations) in some amino acids in various sequences. 
TABLE 5: B cell epitope prediction from $\mathrm{H}, \mathrm{M}, \mathrm{F}$, and $\mathrm{N}$ proteins; the position of peptides is according to the position of amino acids in the protein of the PPR virus.

\begin{tabular}{|c|c|c|c|c|c|c|}
\hline H protein & Peptide & Start & End & Length & Emini 1.000 & Kolaskar 1.041 \\
\hline 1 & PHNK & 16 & 19 & 4 & 2.683 & 0.969 \\
\hline 2 & SIDHQ & 83 & 87 & 5 & 1.169 & 1.03 \\
\hline 3 & PPERV $^{\#}$ & 142 & 146 & 5 & 1.904 & 1.047 \\
\hline 4 & TVTL & 305 & 308 & 4 & 0.505 & 1.113 \\
\hline 5 & TLGG & 330 & 333 & 4 & 0.462 & 0.977 \\
\hline 6 & EANWVVPSTDVRDLQ & 362 & 376 & 15 & 1.022 & 1.039 \\
\hline 7 & KTRPPSFCNGTG & 387 & 398 & 12 & 1.314 & 0.982 \\
\hline 8 & GPWSEGRIP & 400 & 408 & 9 & 1.023 & 0.962 \\
\hline 9 & DVSR & 530 & 533 & 4 & 1.29 & 1.034 \\
\hline $\mathrm{M}$ protein & Peptide & Start & End & Length & Emini 1.000 & Kolaskar 1.037 \\
\hline 1 & SAWDV & 10 & 14 & 5 & 0.533 & 1.044 \\
\hline 2 & GDRK & 43 & 46 & 4 & 2.478 & 0.886 \\
\hline 3 & EDNDPLSP* & 60 & 67 & 8 & 3.167 & 0.969 \\
\hline 4 & DPLSP*\# & 63 & 67 & 5 & 1.332 & 1.051 \\
\hline 5 & VGRT & 69 & 72 & 4 & 0.795 & 1.01 \\
\hline 6 & PEEL & 87 & 90 & 4 & 1.464 & 1.004 \\
\hline 7 & DNGYYS* & 167 & 172 & 6 & 2.116 & 0.975 \\
\hline 8 & INDD & 325 & 328 & 4 & 1.203 & 0.915 \\
\hline $\mathrm{F}$ protein & Peptide & Start & End & Length & Emini 1.000 & Kolaskar 1.054 \\
\hline 1 & TGSA & 34 & 37 & 4 & 0.867 & 0.965 \\
\hline 2 & SNQA & 153 & 156 & 4 & 1.691 & 0.967 \\
\hline 3 & SLRDP & 216 & 220 & 5 & 2.058 & 1.013 \\
\hline 4 & QEWYT & 305 & 309 & 5 & 2.625 & 0.966 \\
\hline 5 & VFTP & 331 & 334 & 4 & 0.643 & 1.112 \\
\hline 6 & GTVC & 336 & 339 & 4 & 0.255 & 1.144 \\
\hline 7 & GSTKS & 357 & 361 & 5 & 1.888 & 0.947 \\
\hline 8 & QDPDK & 402 & 406 & 5 & 5.498 & 0.948 \\
\hline 9 & VGSREYPD & 428 & 435 & 8 & 2.837 & 1.01 \\
\hline 10 & LKPDLTGTSKS & 531 & 541 & 11 & 3.269 & 0.996 \\
\hline $\mathrm{N}$ protein & Peptide & Start & End & Length & Emini 1.000 & Kolaskar 1.014 \\
\hline 1 & DKAPTASGSGGAI* & 16 & 28 & 13 & 0.249 & 0.981 \\
\hline 2 & IPGDSSI & 39 & 45 & 7 & 0.345 & 1.019 \\
\hline 3 & GDPDINGS & 60 & 67 & 8 & 0.735 & 0.935 \\
\hline 4 & TDDPDV & 92 & 97 & 6 & 1.569 & 0.992 \\
\hline 5 & STRSQS & 107 & 112 & 6 & 2.397 & 0.972 \\
\hline 6 & GADLD* & 120 & 124 & 5 & 0.619 & 0.984 \\
\hline 7 & VTAPDTAADS & 182 & 191 & 10 & 0.594 & 1.02 \\
\hline 8 & RTPGNKPR & 242 & 249 & 8 & 4.853 & 0.92 \\
\hline 9 & KFSA & 323 & 326 & 4 & 0.83 & 1.024 \\
\hline 10 & RGTGPRQA* & 408 & 415 & 8 & 1.69 & 0.943 \\
\hline
\end{tabular}

${ }^{*}$ Peptides revealed a higher score if they were shortened in all tools. ${ }^{*}$ Epitopes that passed all the B cell prediction methods and were proposed as B cell epitopes.

3.3. Prediction of B Cell Epitopes. B cell epitope prediction methods aimed are at identifying the antigens recognized by B lymphocytes to initiate humoral immunity [24]. The important criteria for selecting a potential epitope for vaccine development are surface accessibility, hydrophobicity, flexi- bility, and antigenicity [40]. The predicted epitopes should be located on the surface of the cells so that it is more accessible for both the humoral and the cellular immune systems. Antigenicity also is one of the important features of an antigen for vaccine development [40]. Depending on binding 
TABLE 6: Position of CTL epitopes in the H protein, M protein, F protein, and N protein of PPRV that bind with high affinity with the BoLA class I alleles.

\begin{tabular}{|c|c|c|c|c|c|}
\hline \multirow{18}{*}{$\mathrm{H}$ protein } & Peptide & Start & End & Allele & Percentile rank \\
\hline & \multirow{2}{*}{ DLVKFISDK } & \multirow{2}{*}{113} & \multirow{2}{*}{121} & BoLA-T2a & 2 \\
\hline & & & & BoLA-T2C & 1.9 \\
\hline & FLRVFEIGL & 251 & 259 & BoLA-HD6 & 1 \\
\hline & \multirow{2}{*}{ GRIPAYGVI } & \multirow{2}{*}{405} & \multirow{2}{*}{413} & BoLA-D18.4 & 2.3 \\
\hline & & & & BoLA-T2b & 2.1 \\
\hline & \multirow{2}{*}{ LLAIAGIRL } & \multirow{2}{*}{52} & \multirow{2}{*}{60} & BoLA-HD6 & 1.5 \\
\hline & & & & BoLA-T2b & 2.3 \\
\hline & LSLIGLLAI & 47 & 55 & BoLA-T2a & 2.9 \\
\hline & LVKFISDKI & 114 & 122 & BoLA-HD6 & 1.3 \\
\hline & \multirow{4}{*}{ MFLSLIGLL } & \multirow{4}{*}{45} & \multirow{4}{*}{53} & BoLA-HD6 & 2.1 \\
\hline & & & & BoLA-JSP.1 & 1.7 \\
\hline & & & & BoLA-T2b & 1.4 \\
\hline & & & & BoLA-T2C & 1.7 \\
\hline & \multirow{2}{*}{ VMFLSLIGL } & \multirow{2}{*}{44} & \multirow{2}{*}{52} & BoLA-JSP.1 & 2.6 \\
\hline & & & & BoLA-T2C & 1.7 \\
\hline & WCYHDCLIY & 578 & 586 & BoLA-T2a & 1.2 \\
\hline & WSEGRIPAY & 402 & 410 & BoLA-JSP.1 & 2.2 \\
\hline \multirow{11}{*}{$\mathrm{M}$ protein } & SAWDVKGSI & 10 & 18 & BoLA-HD6 & 1.8 \\
\hline & EELLREATE & 88 & 96 & BoLA-T2b & 1 \\
\hline & ELLREATEL & 89 & 97 & BoLA-HD6 & 1.3 \\
\hline & PQRFRVVYM & 152 & 160 & BoLA-JSP.1 & 1.7 \\
\hline & HVGNFRRKK & 220 & 228 & BoLA-T2a & 2.4 \\
\hline & GGIGGTSLH & 251 & 259 & BoLA-T2a & 2 \\
\hline & LHAQLGFKK & 270 & 278 & BoLA-T2a & 1.2 \\
\hline & AQLGFKKIL & 272 & 280 & BoLA-T2C & 2.4 \\
\hline & \multirow{2}{*}{ FKKILCYPL } & \multirow{2}{*}{276} & \multirow{2}{*}{284} & BoLA-D18.4 & 1.2 \\
\hline & & & & BoLA-HD6 & 1.3 \\
\hline & EFRVYDDVI & 316 & 324 & BoLA-HD6 & 2.6 \\
\hline \multirow{20}{*}{$\mathrm{F}$ protein } & AGVALHQSL & 129 & 137 & BoLA-T2C & 1.7 \\
\hline & ASVLCKCYT & 387 & 395 & BoLA-T2a & 1.4 \\
\hline & AYPTLSEIK & 280 & 288 & BoLA-T2a & 2.9 \\
\hline & \multirow{2}{*}{ CSQNALYPM } & 339 & 347 & BoLA-JSP.1 & 2.3 \\
\hline & & צנכנ & 347 & BoLA-T2a & 2.5 \\
\hline & DETSCVFTP & 326 & 334 & BoLA-T2b & 2.7 \\
\hline & DLGPAISLE & 443 & 451 & BoLA-T2C & 1.3 \\
\hline & EKLDVGTNL & 451 & 459 & BoLA-T2b & 2.7 \\
\hline & GSTKSCART & 357 & 365 & BoLA-T2a & 2.6 \\
\hline & GTVCSONAI & 336 & 344 & BoLA-JSP.1 & 2.5 \\
\hline & GIVCSQRAL & 300 & 344 & BoLA-T2b & 1.6 \\
\hline & GVALHQSLM & 130 & 138 & BoLA-HD6 & 2.1 \\
\hline & IAYPTI SEI & 279 & 287 & BoLA-HD6 & 2.9 \\
\hline & 1Л 111 LVLA & 213 & 201 & BoLA-JSP.1 & 2.3 \\
\hline & & & & BoLA-D18.4 & 2.1 \\
\hline & IDLGPAISL & 442 & 450 & BoLA-T2b & 1.4 \\
\hline & & & & BoLA-T2C & 1.2 \\
\hline & IQALSYALG & 227 & 235 & BoLA-T2b & 2.7 \\
\hline & IQVGSREYP & 426 & 434 & BoLA-D18.4 & 2.8 \\
\hline & KGIKARVTY & 259 & 267 & BoLA-D18.4 & 1.2 \\
\hline
\end{tabular}


TABle 6: Continued.

\begin{tabular}{|c|c|c|c|c|c|}
\hline & KPDLTGTSK & 532 & 540 & BoLA-T2a & 2.6 \\
\hline & LEKLDVGTN & 450 & 458 & BoLA-T2b & 3 \\
\hline & LIANCASVL & 382 & 390 & BoLA-HD6 & 1.6 \\
\hline & LSKGNLIAN & 377 & 385 & BoLA-T2a & 3 \\
\hline & I SYAI GGDI & 230 & 238 & BoLA-HD6 & 1.8 \\
\hline & LSI ALUUDI & 200 & 2000 & BoLA-JSP.1 & 1.2 \\
\hline & NALYPMSPL & 342 & 350 & BoLA-T2b & 1.5 \\
\hline & PMSPLLQEC & 346 & 354 & BoLA-T2C & 3 \\
\hline & RFILSKGNL & 374 & 382 & BoLA-T2b & 2 \\
\hline & SIQALSYAL & 226 & 234 & BoLA-T2b & 1 \\
\hline & SIMNSOAIF & 136 & 144 & BoLA-D18.4 & 3 \\
\hline & SLVINSQRAIL & 100 & 144 & BoLA-T2C & 2.5 \\
\hline & & & & BoLA-D18.4 & 2.7 \\
\hline & SQNALYPMS & 340 & 348 & BoLA-HD6 & 1.7 \\
\hline & & & & BoLA-D18.4 & 2.3 \\
\hline & & & & BoLA-D18.4 & 3 \\
\hline & & & & BoLA-HD6 & 2.7 \\
\hline & STKSCARTL & 358 & 366 & BoLA-JSP.1 & 1.6 \\
\hline & & & & BoLA-T2b & 2.9 \\
\hline & & & & BoLA-T2C & 2.7 \\
\hline & TGTSKSYVR & 536 & 544 & BoLA-T2a & 2.9 \\
\hline & TKSCARTLV & 359 & 367 & BoLA-D18.4 & 2.3 \\
\hline & TI SEIKGVI & 283 & & BoLA-D18.4 & 2.4 \\
\hline & ILSEIKGVI & 283 & 291 & BoLA-T2C & 1.8 \\
\hline & YVATOCYI & 314 & 322 & BoLA-HD6 & 2 \\
\hline & IVATCUILI & 314 & 322 & BoLA-T2C & 2.8 \\
\hline & & & & BoLA-D18.4 & 1.6 \\
\hline & ATLLKSLAI & 2 & 10 & BoLA-JSP.1 & 1.3 \\
\hline & AILLNOLAL & 2 & 10 & BoLA-T2a & 2.6 \\
\hline & & & & BoLA-T2b & 1.9 \\
\hline & & & & BoLA-D18.4 & 2.6 \\
\hline & TLLKSLALF & 3 & 11 & BoLA-HD6 & 3 \\
\hline & & & & BoLA-T2C & 1.3 \\
\hline & & & & BoLA-HD6 & 2.2 \\
\hline & OOI GFVAPY & 304 & 312 & BoLA-JSP.1 & 3 \\
\hline & QQLUEV AFI & 304 & 312 & BoLA-T2a & 1.4 \\
\hline & & & & BoLA-T2b & 2.9 \\
\hline & & & & BoLA-JSP.1 & 1.3 \\
\hline $\mathrm{N}$ protein & YFDPAYFRL & 356 & 364 & BoLA-T2b & 2.4 \\
\hline & & & & BoLA-T2C & 1.5 \\
\hline & & & & BoLA-HD6 & 1.6 \\
\hline & AYFRLGQEM & 360 & 368 & BoLA-JSP.1 & 2.1 \\
\hline & & & & BoLA-T2C & 2.9 \\
\hline & & & & BoLA-JSP.1 & 1.7 \\
\hline & PRQAQVSFL & 412 & 420 & BoLA-T2b & 2.2 \\
\hline & & & & BoLA-T2C & 2.6 \\
\hline & & & & BoLA-D18.4 & 1.2 \\
\hline & & & & BoLA-HD6 & 1.2 \\
\hline & RSAEALFRL & 490 & 498 & BoLA-T2a & 1.9 \\
\hline & & & & BoLA-T2b & 2.9 \\
\hline & & & & BoLA-T2C & 2.7 \\
\hline
\end{tabular}




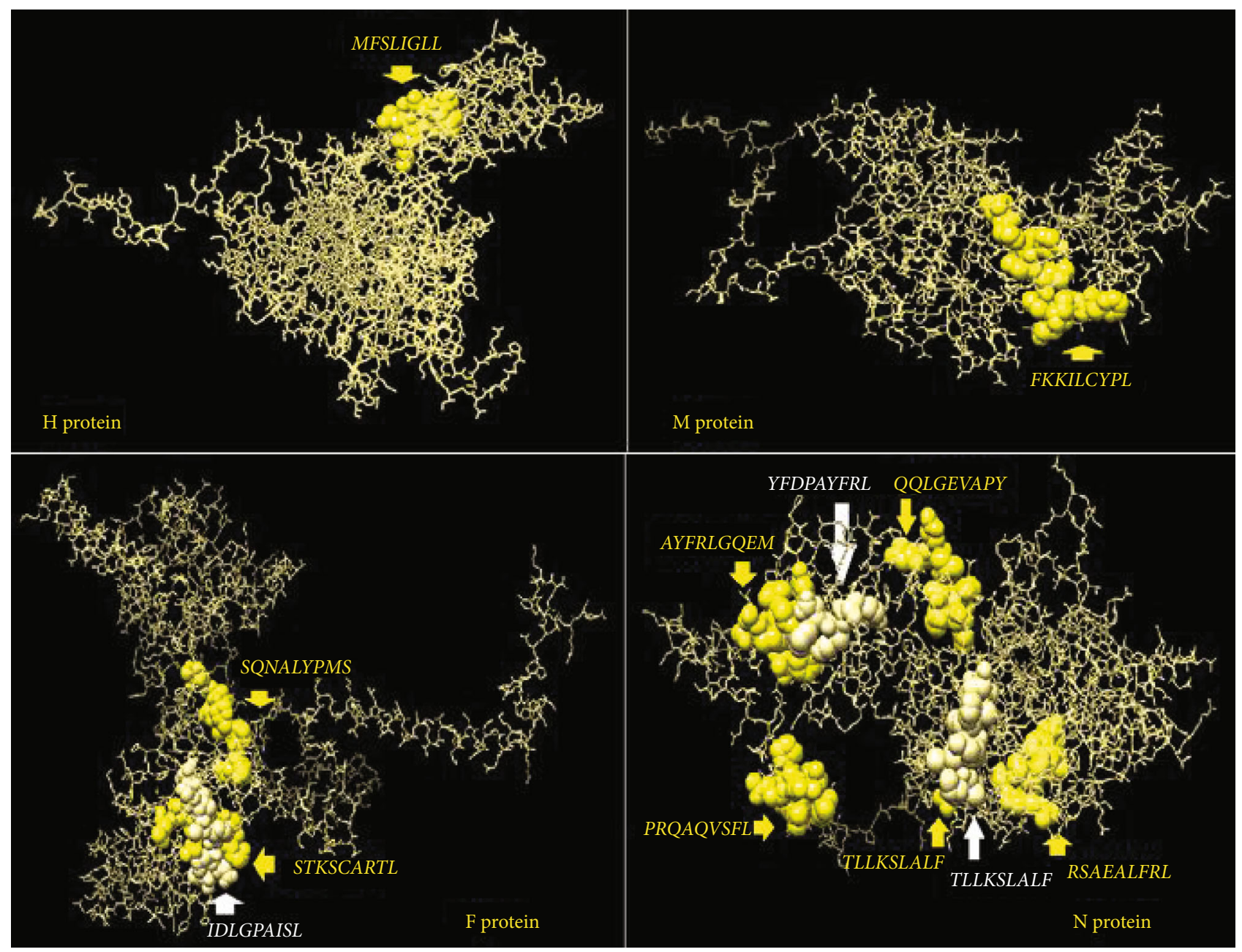

FIGURE 7: The positions of the predicted T cell epitopes in the 3D structure of the reference sequences of PPRV H, M, F, and N proteins.

affinity to B lymphocytes, the BepiPred linear epitope prediction method predicted nine linear epitopes from the $\mathrm{H}$ protein, eight epitopes from $M$ proteins, and ten epitopes for each of the $\mathrm{F}$ and $\mathrm{N}$ proteins. Analysis of these linear epitopes for surface accessibility proposed seven surface epitopes from each of the $\mathrm{H}$ and $\mathrm{F}$ proteins, six epitopes from the $\mathrm{M}$ protein, and four epitopes from the $\mathrm{N}$ protein.

As shown in Figure 4, the threshold values were 0.350 and 1.000 for all epitopes predicted through the BepiPred linear epitope (conserved epitopes) and Emini prediction methods (surface accessibility), respectively. The antigenicity prediction method proposed only two epitopes for all test immunogenic proteins of PPRV. Also, Figure 4 shows that the antigenic epitopes were predicted from $\mathrm{H}, \mathrm{M}, \mathrm{F}$, and $\mathrm{N}$ proteins using the Kolaskar and Tongaonkar antigenicity method under threshold values of $1.014,1.037,1.054$, and 1.014 , respectively. However, no epitopes successfully passed the threshold for the $\mathrm{F}$ and $\mathrm{N}$ proteins.

Only one epitope from each of the $\mathrm{H}$ and $\mathrm{M}$ proteins successfully overlapped all the B cell antigenic index prediction methods. Namely, these epitopes were ${ }_{142} P P E R V_{146}$ from the $\mathrm{H}$ protein and ${ }_{63} D P L S P_{67}$ from the $M$ protein. The
3D structure of the four proteins $(\mathrm{H}, \mathrm{M}, \mathrm{F}$, and $\mathrm{N})$ is shown in Figure 5. The positions of the best $\mathrm{B}$ cells that predicted epitopes from the $\mathrm{H}$ and $\mathrm{M}$ proteins are demonstrated in Figure 6. The overall predicted epitopes from the four proteins are illustrated in Table 5.

3.4. Prediction of CTL Epitopes That Interacted with MHC Class I (BoLA Alleles). CD8+ and CD4+ T cells have a principal role in the stimulation of immune response as well as antigen-mediated clonal expression of the B cell [14]. Unfortunately, the bovine genome project did not assemble a complete sequence of the bovine MHC-II locus [41-43]. Thus, the analysis was completed with BoLA MHC-I alleles only. Cell-mediated immunity induced by cytotoxic T lymphocytes (CTLs) is vital for the defense against viral diseases. CTLs are responsible for the immune elimination of intracellular pathogens such as viruses because these cells recognize the presented endogenous antigenic peptides by the MHC class I molecules [44].

In this study, MHC-I binding prediction methods using the IEDB database predicted different CTL epitopes that strongly interacted with various BoLA alleles. The 
fusion (F) protein proposed a higher number of predicted epitopes with strong interaction with BoLA alleles. Ten epitopes were proposed based on the number of the interacted alleles. The best one was ${ }_{358} S T K S C A R T L_{366}$ that associated with five alleles, followed by ${ }_{442} I D L G-$ PAISL $_{450}$ and ${ }_{340} S_{Q} Q N A L Y P M S_{348}$ as they linked to three alleles each. However, seven epitopes, namely, ${ }_{339}$ CSQNALYPMS $_{347},{ }_{336}$ GTVCSQNAL $_{344},{ }_{279}$ IAYPTLSEI $_{287}$, ${ }_{230} L_{S Y A L G G D I}{ }_{238}, \quad{ }_{136} S L M N S Q A I E_{144},{ }_{283}$ TLSEIKGVI $_{291}$, and ${ }_{314} Y V A T Q G Y L I_{322}$ were predicted to interact with two alleles.

The nucleoprotein $(\mathrm{N})$ also displayed strong interaction activity with BoLA alleles. Seven epitopes were proposed with strong interaction with BoLA alleles. The top N protein epitope was ${ }_{490} R S A E A L F R L_{498}$ which was associated with five alleles, followed by two epitopes, namely, ${ }_{2} A T L L K S L A L_{10}$, and ${ }_{304} Q Q L G E V A P Y_{312}$ that linked to four alleles each. In addition to that, four epitopes ${ }_{3} T L L K S L A L F_{11},{ }_{356} Y F D-$ $P_{P A Y R L}{ }_{364},{ }_{360} A Y F R L G Q E M_{368}$, and ${ }_{412} P_{R Q A Q V S F L} 420$ interacted with three bovine alleles each. Surprisingly, these two proteins ( $\mathrm{F}$ and $\mathrm{N}$ ) achieved promising results in CTL prediction methods, although they failed to predict any epitope carrying all the ideal traits in B cells.

The haemagglutinin $(\mathrm{H})$ protein predicted five CTL epitopes, but one epitope was predicted as the best peptide, ${ }_{45}$ MFLSLIGLL $_{53}$, as it linked to four BoLA alleles, followed by four peptides that interacted with two alleles each. They were ${ }_{113} D L V K F I S D K_{121}$, ${ }_{405}$ GRIPAYGVI $_{413},{ }_{52}$ LLAIAGIRL $_{60}$, and ${ }_{44}$ VMFLSLIGL $L_{52}$. However, this protein showed a somewhat satisfactory result in $\mathrm{B}$ and $\mathrm{T}$ cell prediction methods. The M protein showed unsatisfactory results in CTL prediction methods different from that predicted by $\mathrm{B}$ cell methods. The results suggested only one epitope; ${ }_{276}$ FKKILCYPL ${ }_{284}$ interacted with only two alleles. The overall epitopes that were proposed to interact with CTL alleles are illustrated in Table 6 for all proteins. The positions of the best CTLpredicted epitopes in their immunogenic protein structure are shown in Figure 7.

Vaccination is considered the most effective way of controlling PPR. The infection by morbillivirus is associated with severe immunosuppression that is characterized by a massive virus-specific immune response. Protection is mediated by cell-mediated and humoral immune responses directed mainly against particular proteins in the viral structure. These proteins included $\mathrm{H}, \mathrm{F}$, and $\mathrm{N}$ proteins [45-47]. It was reported that the envelope glycoproteins $\mathrm{H}$ and $\mathrm{F}$ of PPRV demonstrated a protective and neutralizing antibody response $[3,48-50]$. In this study, using the immunoinformatics prediction methods, the $\mathrm{H}$ protein demonstrated affinity to interact with $B$ cells that was characterized by antibody production. This result coincided with the previously published reports [3, 48-50], while the F protein failed to interact with B cells; i.e., no epitopes from the $\mathrm{F}$ protein had passed the threshold of the B cell prediction methods. However, this protein revealed multiple predicted epitopes that demonstrated high affinity to the alleles of CTLs. The M protein which is believed to play a very significant role in morbillivirus assembly and budding by concentrating the $\mathrm{F}, \mathrm{H}$, and $\mathrm{N}$ proteins at the virus-assembly site $[16,17]$ showed moderate affinity to B cells. One epitope from the $\mathrm{M}$ protein as well as the $\mathrm{H}$ protein was predicted as a $B$ cell epitope. Moreover, the $\mathrm{M}$ protein revealed multiple epitopes that interacted with CTLs of the cell-mediated immunity. This result indicated that the $\mathrm{M}$ protein besides its role in the virus assembly may also contain antigenic determinants that could be elected as vaccine candidates.

In addition to that, cell-mediated immunity plays a role in protection against the viral infection. Despite the $\mathrm{N}$ protein being the most frequent viral protein in PPRV, it does not induce a neutralizing antibody response in the host [50]. However, it has been found to induce a strong cellmediated immune response, which is believed to contribute to protection. Here, in this report, the same result was obtained. The $\mathrm{N}$ protein demonstrated no affinity to elicit the humoral immune response. However, it showed favorable affinity to interact with a cell-mediated response. It is noteworthy that five out of seven epitopes predicted from the nucleoprotein of PPRV in this study were found to be proposed by another in silico study using mouse alleles and NetMHCI methods [51]. The proposed epitopes from that study were ATLLKSLAL, TLLKSLALF, YFDPAYFRL, $A Y F R L G Q E M$, and RSAEALFRL. Thus, the predictions for the different epitopes that bound to different alleles particularly from the $\mathrm{N}$ protein of PPRV were somewhat in agreement regardless of the alleles (cow and mouse alleles) and algorithm used (ANN, NetMHCI).

In general, epitope-based vaccines that are chemically well-characterized have become desirable candidate vaccines due to their relative ease of production and construction, chemical stability, and lack of infectious potential [52]. Many in silico studies have shown the value of using prediction programs to evaluate the efficiency of binding of putative epitopes to various human and animal alleles [33, 52-55].

\section{Conclusion}

This study focused mainly on the production of a peptide vaccine against $\mathrm{H}, \mathrm{M}, \mathrm{F}$, and $\mathrm{N}$ proteins of $\mathrm{PPRV}$ using immunoinformatics tools. Epitopes that showed conservancy and high binding affinities to many MHC alleles are considered the best candidates for in vitro and in vivo testing. Epitopes that were predicted from $\mathrm{B}$ cell prediction methods like ${ }_{142} P P E R V_{146}$ and ${ }_{305} T V T L_{308}$ from the $\mathrm{H}$ protein and ${ }_{63} D P L S P_{67}$ and ${ }_{64} P L S P_{67}$ from the $\mathrm{M}$ protein could act as good $\mathrm{B}$ cell epitopes to induce humoral immunity. While the $\mathrm{F}$ and $\mathrm{N}$ proteins failed to fulfill all $\mathrm{B}$ cell indexes used in this study for the prediction of promising epitopes, however, these proteins predicted epitopes that interacted with various BoLA MHC-I alleles. For instance, the best epitopes were predicted from $\mathrm{F}$ $\left({ }_{358} S_{T K S C A R T L}{ }_{366}\right)$ and $\mathrm{N}\left({ }_{490} R S A E A L F R L_{498}\right)$ proteins as they interacted with five MHC-I BoLA alleles, followed by ${ }_{45} M F L S L I G L L_{53}$ proposed from the $\mathrm{H}$ protein and linked with four alleles, while the ${ }_{276} F K K I L C Y P L_{284}$ epitope was predicted from the M protein linked with only two alleles. Although bioinformatics studies have been established to facilitate the peptide design, not all peptides that are predicted in silico are optimally immunogenic in vivo and it remains necessary to test the expected peptides in vivo to ensure that the $\mathrm{T}$ cell responses are elicited. 


\section{Data Availability}

The [retrived strains, IEDB analysis methods] data used to support the findings of this study are included within the article.

\section{Conflicts of Interest}

The authors declare that they have no competing interests.

\section{Acknowledgments}

The authors would like to thank the staff members of the College of Veterinary Medicine, University of Bahri, Sudan, for their cooperation and support.

\section{References}

[1] C. Schulz, C. Fast, K. Schlottau, B. Hoffmann, and M. Beer, "Neglected hosts of small ruminant morbillivirus," Emerging Infectious Diseases, vol. 24, no. 12, pp. 2334-2337, 2018.

[2] FAO, O, Global strategy for the control and eradication of $P P R$, FAO and OIE, 2015.

[3] M. Munir, "Peste des petits ruminants virus," in Mononegaviruses of Veterinary Importance. Volume I: Pathobiology and Molecular Diagnosis, pp. 65-98, CAB International, Oxfordshire, 2013.

[4] A. C. Banyard, S. Parida, C. Batten, C. Oura, O. Kwiatek, and G. Libeau, "Global distribution of peste des petits ruminants virus and prospects for improved diagnosis and control," Journal of General Virology, vol. 91, no. 12, pp. 2885-2897, 2010.

[5] O. Kwiatek, Y. H. Ali, I. K. Saeed et al., "Asian lineage of peste des petits ruminants virus, Africa," Emerging Infectious Diseases, vol. 17, no. 7, pp. 1223-1231, 2011.

[6] O. Kwiatek, C. Minet, C. Grillet et al., "Peste des petits ruminants (PPR) outbreak in Tajikistan," Journal of Comparative Pathology, vol. 136, no. 2-3, pp. 111-119, 2007.

[7] N. Kerur, M. K. Jhala, and C. G. Joshi, "Genetic characterization of Indian peste des petits ruminants virus (PPRV) by sequencing and phylogenetic analysis of fusion protein and nucleoprotein gene segments," Research in Veterinary Science, vol. 85, no. 1, pp. 176-183, 2008.

[8] B. el Hag Ali and W. P. Taylor, "Isolation of peste des petits ruminants virus from the Sudan," Research in Veterinary Science, vol. 36, no. 1, pp. 1-4, 1984.

[9] M. S. Shaila, D. Shamaki, M. A. Forsyth et al., "Geographic distribution and epidemiology of peste des petits ruminants viruses," Virus Research, vol. 43, no. 2, pp. 149-153, 1996.

[10] T. Barrett, I. K. G. Visser, L. Mamaev, L. Goatley, M. F. van Bressem, and A. D. M. E. Osterhaus, "Dolphin and porpoise morbilliviruses are genetically distinct from phocine distemper virus," Virology, vol. 193, no. 2, pp. 1010-1012, 1993.

[11] Z. Wang, J. Bao, X. Wu et al., "Peste des petits ruminants virus in Tibet, China," Emerging Infectious Diseases, vol. 15, no. 2, pp. 299-301, 2009.

[12] M. Mahapatra, S. Parida, B. G. Egziabher, A. Diallo, and T. Barrett, "Sequence analysis of the phosphoprotein gene of peste des petits ruminants (PPR) virus: editing of the gene transcript," Virus Research, vol. 96, no. 1-2, pp. 85-98, 2003.

[13] A. C. Banyard, R. J. Grant, C. H. Romero, and T. Barrett, "Sequence of the nucleocapsid gene and genome and antige- nome promoters for an isolate of porpoise morbillivirus," Virus Research, vol. 132, no. 1-2, pp. 213-219, 2008.

[14] P. Dhar, D. Muthuchelvan, A. Sanyal et al., "Sequence analysis of the haemagglutinin and fusion protein genes of peste-despetits ruminants vaccine virus of Indian origin," Virus Genes, vol. 32, no. 1, pp. 71-78, 2006.

[15] G. Berhe, C. Minet, C. le Goff et al., "Development of a dual recombinant vaccine to protect small ruminants against peste-des-petits-ruminants virus and capripoxvirus infections," Journal of Virology, vol. 77, no. 2, pp. 1571-1577, 2003.

[16] A. Haffar, G. Libeau, A. Moussa, M. Cécile, and A. Diallo, "The matrix protein gene sequence analysis reveals close relationship between peste des petits ruminants virus (PPRV) and dolphin morbillivirus," Virus Research, vol. 64, no. 1, pp. 69-75, 1999.

[17] G. D. Maganga, D. Verrier, R. M. Zerbinati, C. Drosten, J. F. Drexler, and E. M. Leroy, "Molecular typing of PPRV strains detected during an outbreak in sheep and goats in southeastern Gabon in 2011," Virology Journal, vol. 10, no. 1, p. 82, 2013.

[18] A. Diallo, "Control of peste des petits ruminants: classical and new generation vaccines," Developments in Biologicals, vol. 114, pp. 113-119, 2003.

[19] W. G. Dundon, C. Adombi, A. Waqas et al., "Full genome sequence of a peste des petits ruminants virus (PPRV) from Ghana," Virus Genes, vol. 49, no. 3, pp. 497-501, 2014.

[20] I. K. Saeed, Y. H. Ali, A. M. I. Khalafalla, and E. A. RahmanMahasin, "Current situation of peste des petits ruminants (PPR) in the Sudan," Tropical Animal Health and Production, vol. 42, no. 1, pp. 89-93, 2010.

[21] J. M. Gershoni, A. Roitburd-Berman, D. D. Siman-Tov, N. Tarnovitski Freund, and Y. Weiss, "Epitope mapping: the first step in developing epitope-based vaccines," BioDrugs, vol. 21, no. 3, pp. 145-156, 2007.

[22] S. Iurescia, D. Fioretti, V. M. Fazio, and M. Rinaldi, "Epitopedriven DNA vaccine design employing immunoinformatics against B-cell lymphoma: a biotech's challenge," Biotechnology Advances, vol. 30, no. 1, pp. 372-383, 2012.

[23] A. H. Abu haraz, K. A. Abd elrahman, M. S. Ibrahim et al., "Multi epitope peptide vaccine prediction against Sudan ebola virus using immuno-informatics approaches," Advanced Techniques in Biology \& Medicine, vol. 5, no. 1, p. 203, 2017.

[24] J. Zheng, X. Lin, X. Wang et al., "In silico analysis of epitopebased vaccine candidates against hepatitis B virus polymerase protein," Viruses, vol. 9, no. 5, p. 112, 2017.

[25] K. Tamura, G. Stecher, D. Peterson, A. Filipski, and S. Kumar, "MEGA6: molecular evolutionary genetics analysis version 6.0," Molecular Biology and Evolution, vol. 30, no. 12, pp. 2725-2729, 2013.

[26] T. Hall, "BioEdit: an important software for molecular biology," GERF Bulletin of Biosciences, vol. 2, no. 1, pp. 60-61, 2011.

[27] R. Vita, J. A. Overton, J. A. Greenbaum et al., "The immune epitope database (IEDB) 3.0," Nucleic Acids Research, vol. 43, no. D1, pp. D405-D412, 2015.

[28] J. Larsen, O. Lund, and M. Nielsen, "Improved method for predicting linear B-cell epitopes," Immunome Research, vol. 2, no. 1, p. 2, 2006.

[29] E. A. Emini, J. V. Hughes, D. S. Perlow, and J. Boger, "Induction of hepatitis A virus-neutralizing antibody by a virus- 
specific synthetic peptide," Journal of Virology, vol. 55, no. 3, pp. 836-839, 1985.

[30] A. S. Kolaskar and P. C. Tongaonkar, "A semi-empirical method for prediction of antigenic determinants on protein antigens," FEBS Letters, vol. 276, no. 1-2, pp. 172-174, 1990.

[31] C. Lundegaard, O. Lund, and M. Nielsen, "Accurate approximation method for prediction of class I MHC affinities for peptides of length 8,10 and 11 using prediction tools trained on 9mers," Bioinformatics, vol. 24, no. 11, pp. 1397-1398, 2008.

[32] A. Patronov and I. Doytchinova, "T-cell epitope vaccine design by immunoinformatics," Open Biology, vol. 3, no. 1, article 120139, 2013.

[33] M. Abdelbagi, T. Hassan, M. Shihabeldin et al., "Immunoinformatics prediction of peptide-based vaccine against African horse sickness virus," Immunome Research, vol. 13, no. 2, p. 135, 2017.

[34] M. Källberg, H. Wang, S. Wang et al., "Template-based protein structure modeling using the RaptorX web server," Nature Protocols, vol. 7, no. 8, pp. 1511-1522, 2012.

[35] J. Peng and J. Xu, "RaptorX: exploiting structure information for protein alignment by statistical inference," Proteins: Structure, Function, and Bioinformatics, vol. 79, Supplement 10, pp. 161-171, 2011.

[36] J. Peng and J. Xu, "A multiple-template approach to protein threading," Proteins: Structure, Function, and Bioinformatics, vol. 79, no. 6, pp. 1930-1939, 2011.

[37] Y. Yang, E. Faraggi, H. Zhao, and Y. Zhou, "Improving protein fold recognition and template-based modeling by employing probabilistic-based matching between predicted onedimensional structural properties of query and corresponding native properties of templates," Bioinformatics, vol. 27, no. 15, pp. 2076-2082, 2011.

[38] W. M. Chan, S. E. Rogers, S. M. Nash, P. G. Buning, and R. Meakin, "User's manual for Chimera grid tools, version 1.8," NASA Ames Research Center, 2003, July 2006, http:// people.nas.nasa.gov/ rogers/cgt/doc/man.html.

[39] S. Pahil, N. Taneja, H. R. Ansari, and G. P. S. Raghava, "In silico analysis to identify vaccine candidates common to multiple serotypes of Shigella and evaluation of their immunogenicity," PLoS One, vol. 12, no. 8, article e0180505, 2017.

[40] P. P. Kar and A. Srivastava, "Immuno-informatics analysis to identify novel vaccine candidates and design of a multiepitope based vaccine candidate against Theileria parasites," Frontiers in Immunology, vol. 9, article 2213, 2018.

[41] V. Nene, N. Svitek, P. Toye et al., "Designing bovine T cell vaccines via reverse immunology," Ticks and Tick-borne Diseases, vol. 3, no. 3, pp. 188-192, 2012.

[42] B. G. Sequencing, A. Consortium, C. G. Elsik, R. L. Tellam, and K. C. Worley, "The genome sequence of taurine cattle: a window to ruminant biology and evolution," Science, vol. 324, pp. 522-528, 2009.

[43] A. V. Zimin, A. L. Delcher, L. Florea et al., "A whole-genome assembly of the domestic cow, Bos taurus," Genome Biology, vol. 10, no. 4, article R42, 2009.

[44] T. K. Sahu, A. R. Rao, P. K. Meher, B. C. Sahoo, A. Gupta, and A. Rai, "Computational prediction of MHC class I epitopes for most common viral diseases in cattle (Bos taurus)," Indian Journal of Biochemistry \& Biophysics, vol. 52, no. 1, pp. 3444, 2015.

[45] S. Naik, G. J. Renukaradhya, M. Rajasekhar, and M. S. Shaila, "Immunogenic and protective properties of haemagglutinin protein $(\mathrm{H})$ of rinderpest virus expressed by a recombinant baculovirus," Vaccine, vol. 15, no. 6-7, pp. 603-607, 1997.

[46] S. Naik and M. S. Shaila, "Characterization of membranebound and membrane anchor-less forms of hemagglutinin glycoprotein of rinderpest virus expressed by baculovirus recombinants," Virus Genes, vol. 14, no. 2, pp. 95-104, 1997.

[47] G. Sinnathamby, R. Nayak, and M. S. Shaila, "Mapping of Thelper epitopes of rinderpest virus hemagglutinin protein," Viral Immunology, vol. 14, no. 1, pp. 83-92, 2001.

[48] C. H. Romero, T. Barrett, R. P. Kitching, V. M. Carn, and D. N. Black, "Protection of cattle against rinderpest and lumpy skin disease with a recombinant capripoxvirus expressing the fusion protein gene of rinderpest virus," The Veterinary Record, vol. 135, no. 7, pp. 152-154, 1994.

[49] G. Sinnathamby, G. J. Renukaradhya, M. Rajasekhar, R. Nayak, and M. S. Shaila, "Immune responses in goats to recombinant hemagglutinin-neuraminidase glycoprotein of peste des petits ruminants virus: identification of a T cell determinant,"Vaccine, vol. 19, no. 32, pp. 4816-4823, 2001.

[50] A. Diallo, C. Minet, C. Le Goff et al., "The threat of peste des petits ruminants: progress in vaccine development for disease control," Vaccine, vol. 25, no. 30, pp. 5591-5597, 2007.

[51] B. Baloi, "In silico epitope prediction and 3D model analysis of peste des petits ruminants virus nucleoprotein (PPRV N)," bioRxiv, no. article 095505, 2016.

[52] Y.-F. Liu, C.-Y. Lin, and H.-M. Hong, "In silico design, synthesis and potency of an epitope-based vaccine against foot-andmouth disease virus," International Journal of Pharmacology, vol. 13, no. 2, pp. 122-133, 2017.

[53] S. T. Idris, S. Salih, M. Basheir et al., "In silico prediction of peptide based vaccine against fowlpox virus (FPV)," Immunome Research, vol. 14, no. 2, p. 154, 2018.

[54] S. O. Abd Albagi, O. Hashim Ahmed, M. A. Gumaa, K. A. Abd elrahman, A. H. Abu Haraz, and M. A, "Immunoinformaticspeptide driven vaccine and in silico modeling for Duvenhage rabies virus glycoprotein G," Journal of Clinical \& Cellular Immunology, vol. 8, no. 4, p. 517, 2017.

[55] N. Prabdial-Sing, A. J. Puren, and S. M. Bowyer, "Sequencebased in silico analysis of well studied hepatitis $C$ virus epitopes and their variants in other genotypes (particularly genotype 5a) against South African human leukocyte antigen backgrounds," BMC Immunology, vol. 13, no. 1, p. 67, 2012. 


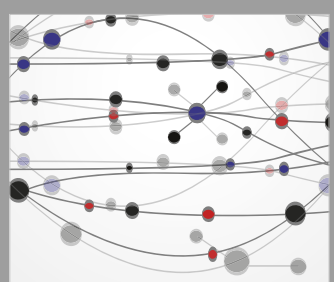

The Scientific World Journal
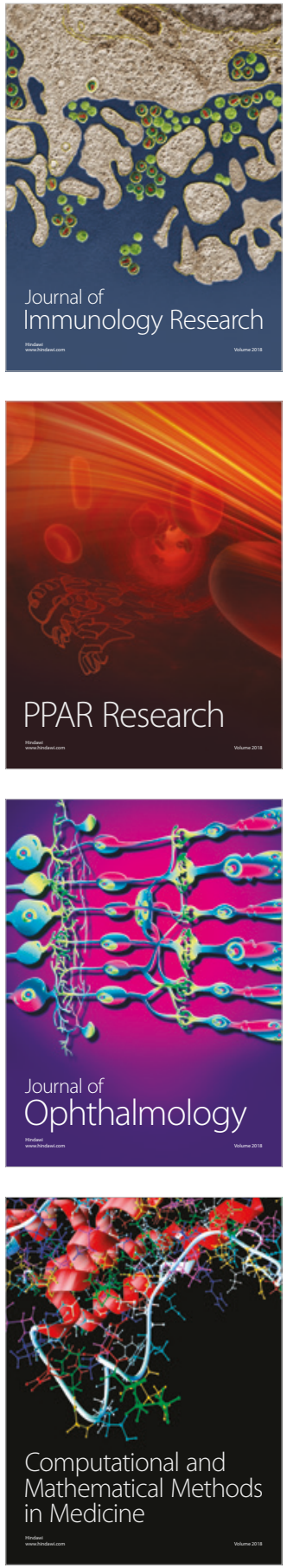

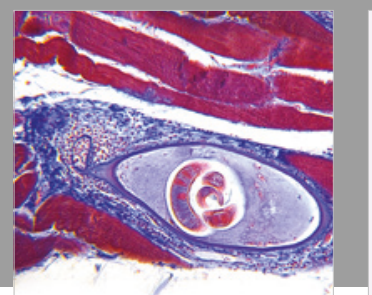

Gastroenterology Research and Practice

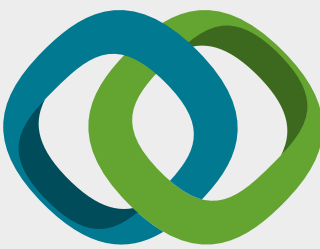

\section{Hindawi}

Submit your manuscripts at

www.hindawi.com
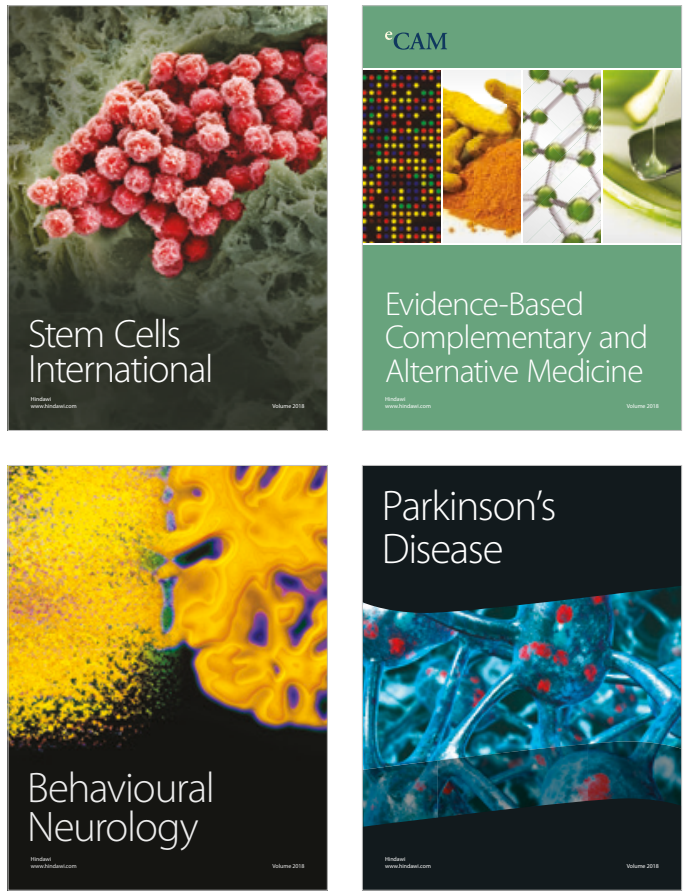

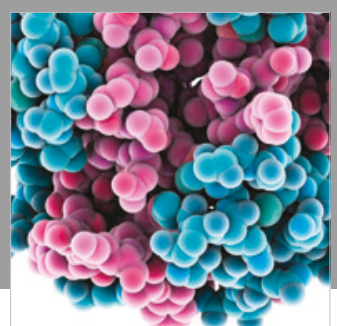

ournal of

Diabetes Research

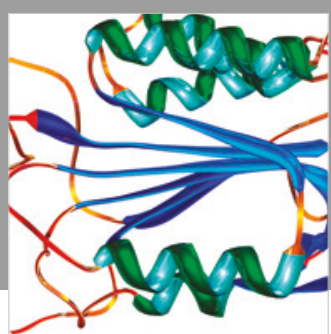

Disease Markers
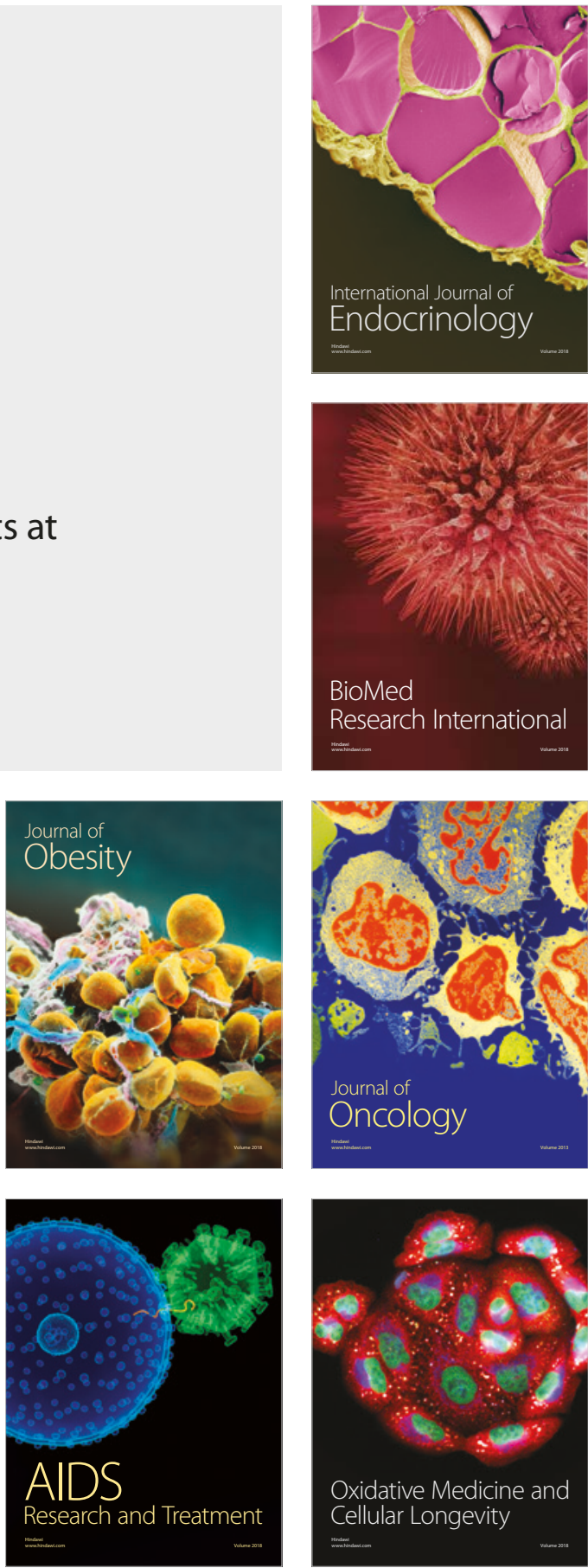